\title{
Fabrication of First 4-m Coils for the LARP MQXFA Quadrupole and Assembly in Mirror Structure
}

\author{
E.F. Holik, G. Ambrosio, M. Anerella, R. Bossert, E. Cavanna, D. Cheng, D.R. Dietderich, P. Ferracin, A.K. Ghosh, \\ S. Izquierdo Bermudez, S. Krave, A. Nobrega, J. C. Perez, I. Pong, G.L. Sabbi, C. Santini, J. Schmalzle, P. \\ Wanderer, $\mathrm{X}$. Wang, and M. Yu
}

\begin{abstract}
The US LHC Accelerator Research Program is constructing prototype interaction region quadrupoles as part of the US in-kind contribution to the Hi-Lumi LHC project. The low-beta MQXFA Q1/Q3 coils have a 4-m length and a $150 \mathrm{~mm}$ bore. The design is first validated on short, one meter models (MQXFS) developed as part of the longstanding $\mathrm{Nb}_{3} \mathrm{Sn}$ quadrupole R\&D by LARP in collaboration with CERN. In parallel, facilities and tooling are being developed and refined at BNL, LBNL, and FNAL to enable long coil production, assembly, and cold testing. Long length scale-up is based on the experience from the LARP $90 \mathrm{~mm}$ aperture (TQ-LQ) and $120 \mathrm{~mm}$ aperture (HQ and Long HQ) programs. A 4-m long MQXF practice coil was fabricated, water jet cut and analyzed to verify procedures, parts, and tooling. In parallel, the first complete prototype coil (QXFP01a) was fabricated and assembled in a long magnetic mirror, MQXFPM1, to provide early feedback on coil design and fabrication following the successful experience of previous LARP mirror tests.
\end{abstract}

Index Terms - High Luminosity LHC, Long Nb3Sn Coil, Mirror Magnet.

\section{INTRODUCTION}

$\mathrm{T}$ $\mathrm{HE}$ advanced superconducting properties of $\mathrm{Nb}_{3} \mathrm{Sn}$ are required in the Interaction Region for the High Luminosity LHC to achieve an integrated luminosity of $3000 \mathrm{fb}^{-1}[1,2]$. The US LHC Accelerator Research Program (LARP) continues to develop $\mathrm{Nb}_{3} \mathrm{Sn}$ IR quads for Hi-Lumi LHC. Initial LARP Technology Quads (TQ) had a bore size of 90 $\mathrm{mm}[3,4]$ and a length of 1 meter. TQ was successfully scaled up to 3.7 meters for the first long $\mathrm{Nb}_{3} \mathrm{Sn}$ quadrupole LQ [5]. The bore size was then increased to $120 \mathrm{~mm}$ in the High-Field Quads (HQ) and became the testing ground for the final 150-

The work of E. F. Holik was supported by the Toohig Fellowship in Accelerator Science from the US LHC Accelerator Research Program. This work was supported by the US Department of Energy through the US LHC Accelerator Research Program (LARP) and by....

E. F. Holik, is with Angelo State University, San Angelo, TX, 76904 USA and Fermi National Accelerator Laboratory, Batavia, IL 60510 USA (e-mail: eholik@fnal.gov).

G. Ambrosio, R. Bossert, S. Krave, A. Nobrega, C. Santini and M. Yu are with the Fermi National Accelerator Laboratory, Batavia, IL 60510 USA

M. Anerella, A. K. Ghosh, J. Schmalzle, and P. Wanderer are with Brookhaven National Laboratory, Upton, NY 11973 USA.

E. Cavanna, P. Ferracin, S. Izquierdo Bermudez, and J. C. Perez are with the European Organization for Nuclear Research (CERN), 1211 Geneva, Switzerland.

D. Cheng, D. R. Dietderich, I. Pong, G. L. Sabbi, and X. Wang are with Lawrence Berkeley National Laboratory, Berkley, CA 94720 USA. mm-aperture MQXF IR quad design. The key features include spliceless two-layer coil design [6], shell based support structure with bladder and key assembly [7-9], provisions to accommodate cable dimensional changes during reaction [10], alignment and field quality [11]. The first long coils were designed to provide 4.0 meters in magnetic length. To increase load line margin, the coils were lengthened to 4.2 meters of magnetic length. The first short 150-mm-apetrure coil was cut to verify fabrication techniques and the first instrumented coil was tested in a mirror structure, MQXFSM01, to offer timely verification of all coil design parameters and fabrication process. The length scale up followed this same approach. The first coil, QXFP01a, was fabricated, fully instrumented, and assembled into a mirror structure.. The mirror test provides early feedback on all coil design and fabrication parameters. A companion coil, QXFP01b, employed $2^{\text {nd }}$ generation QXF radial insulation and was cut and analyzed to verify long coil fabrication process.

\section{MQXFA COIL DESIGN AND FABRICATION}

\section{A. $\mathrm{Nb}_{3} \mathrm{Sn}$ Cable and Insulation}

MQXFA Rutherford cable has 40 strands of Restacked Rod Process conductor made by Oxford Superconducting Technologies with a wire diameter of $0.85 \mathrm{~mm}$. The cable was fabricated at LBNL and insulated with braided-on S2 glass insulation at New England Wire Technologies [12].

\section{B. MQXFA Coil Winding and Curing}

Long coil fabrication is in essence a scaling up of short coil fabrication [13]. For long coils the end regions and final cross section design was optimized for integrated harmonics [14].

Current LHC IR quads built at Fermilab were wound with a Spirex Selva coil winding machine, shown in Fig 1a. The Selva winder was recently refurbished to accommodate winding MQXF coils as well as semi-automated operation. Input controls can be optimized in practice coils, recorded and then repeated for subsequent coils.

Coil Parts, including pole, wedge and end parts were designed, procured and inspected before the coil fabrication [14]. To control part and coil variability, the titanium (Ti-6Al$4 \mathrm{~V})$ pole parts [13] are fabricated with a very tight tolerance of $\pm 25 \mu \mathrm{m}$. The phosphor bronze wedges are extruded using dies with a tolerance of $\pm 50 \mu \mathrm{m}$ according to design. After die fabrication the actual wedges have a variability less than $\pm 25 \mu \mathrm{m}$. 


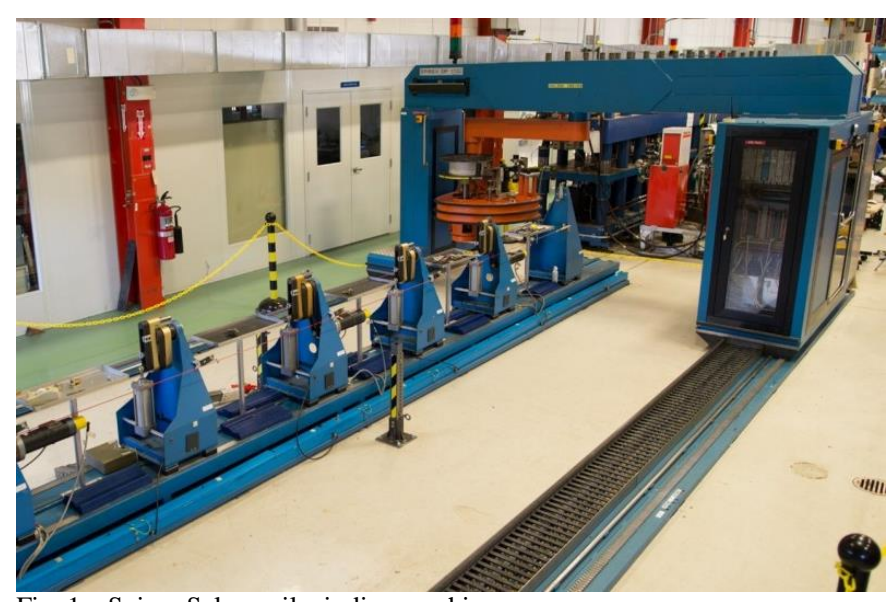

Fig. 1a. Spirex Selva coil winding machine

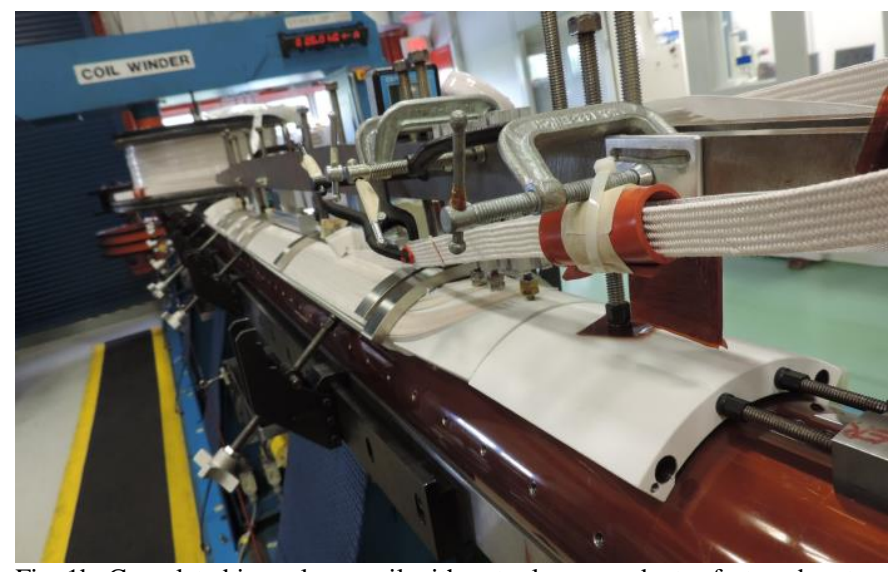

Fig. 1b. Completed inner layer coil with outer layer conductor fastened on top

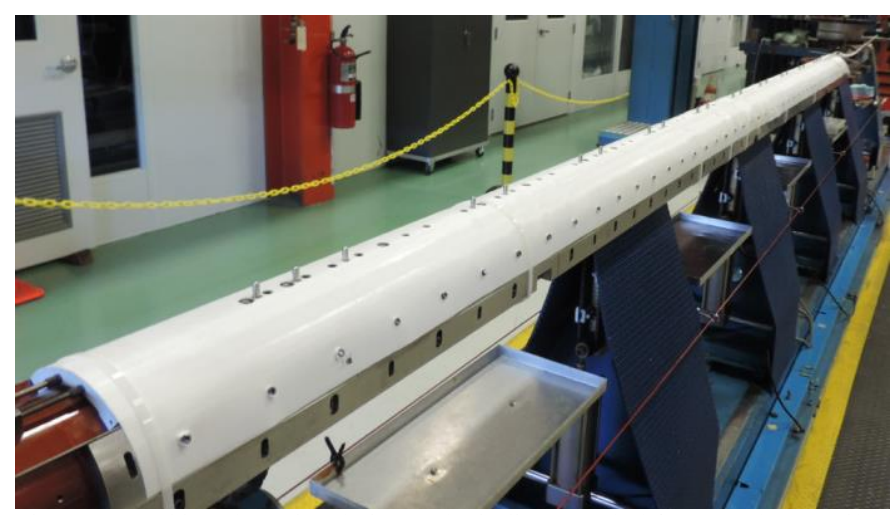

Fig. 1c. Cured interlayer insulation and winding mandrel for outer layer coil

Gaps are left between pole pieces to accommodate conductor length contraction during the $\mathrm{Nb}_{3} \mathrm{Sn}$ formation heat treatment. The initial assumed length contraction is approximately $4 \mathrm{~mm}$ per meter based on short model coil fabrication [15]. For the long coils, the total inner coil layer gap was $15.2 \mathrm{~mm}$ and distributed over 9 gaps. The total outer coil layer gap was $18.95 \mathrm{~mm}$ distributed over 9 gaps as well. Additional gap was left in QXFP01b to prevent straining the coil during cool down and to verify length scale-up. Both coils QXFP01a and QXFP01b scaled linearly with the LARP short coils. The short coils fabricated at CERN have a slightly different cable insulation system and contract less than $1 \mathrm{~mm}$ per meter [16]. This linear scaling for LARP coils further verifies the principal role of braided-on cable insulation on coil contraction [13]. Primary purpose of wedge gaps is same as pole gaps i.e. to allow unconstrained expansion and contraction of the coil. To account for the differential expansion of the copper wedges, five wedge gaps each were used for the inner and outer layers with a total gap of $15.2 \mathrm{~mm}$ and $9.85 \mathrm{~mm}$ respectfully.

The inner and outer layers are wound without a splice between them, using a single piece of insulated Rutherford cable. When the inner layer is wound, the cable reel for the outer layer is fixed on top of the inner layer coil, as shown in Fig. 1b. Reinforcement and additional verification of the long winding mandrel machinery was performed to accommodate extra mass from the cable spool.

A two part ceramic binder (CTD -1202) is applied locally to each turn at the lead and return ends and quickly cured with a heat gun [17]. The ceramic binder acts as a temporary cement to reduce the likelihood of popped strands. After winding the inner layer, the entire coil is painted with binder at a rate of 1.7 grams per meter of cable. Applying binder uniformly for long coils is more difficult than short coils due to different techniques and rates of application. This has resulted in midplane turns slightly detaching from the coil blocks after being cured at $150^{\circ}$ for 6 hours. The issue was corrected for subsequent coils by segmenting the application and specifying techniques.

The cavity size is equal to the final coil cavity size. The outer layer is wound on a cured $660 \mu \mathrm{m}$ thick S2 glass interlayer insulation as shown in Fig. 1c. After winding the outer layer, binder is applied to the outer layer and the whole coil is cured.

\section{MQXFA Reaction and Impregnation}

The MQXF coils are reacted in oxygen free, gas tight oven using an argon gas atmosphere. Coil impregnation occurs at both BNL and FNAL with only a few minor differences in the process in order to use existing equipment at each laboratory. QXFP01a was reacted and impregnated at BNL while QXFP01b was reacted and impregnated at FNAL. The heat treatment cycle for both coils used 3 temperature plateaus of $210^{\circ} \mathrm{C}, 400^{\circ} \mathrm{C}$ and $640^{\circ} \mathrm{C}$ with durations of 72 hours, 48 hours, and 48 hours respectively. There are two argon gas supply lines, one for the sealed reaction tooling and one for the oven volume.

Coil impregnation uses tooling identical in cross section to the reaction tooling. The reacted coil is carefully transferred from the reaction tooling to the impregnation tooling in multiple steps. The outer reaction tooling form blocks are removed to expose the coil outer layer for impregnation preparation. Superconducting NbTi cable leads are soldered to the reacted $\mathrm{Nb}_{3} \mathrm{Sn}$ coil leads with $4 / 96 \mathrm{Sn}-\mathrm{Ag}$ solder and a non-activated flux, MOB 39 [17]. S2 glass sheets and a coil protection trace assembly are installed. When complete, the mold released impregnation tooling form blocks are installed and the assembly is turned over. The process is repeated for the coil inner layer.

Vacuum pressure impregnation (VPI) is used with CTD- 


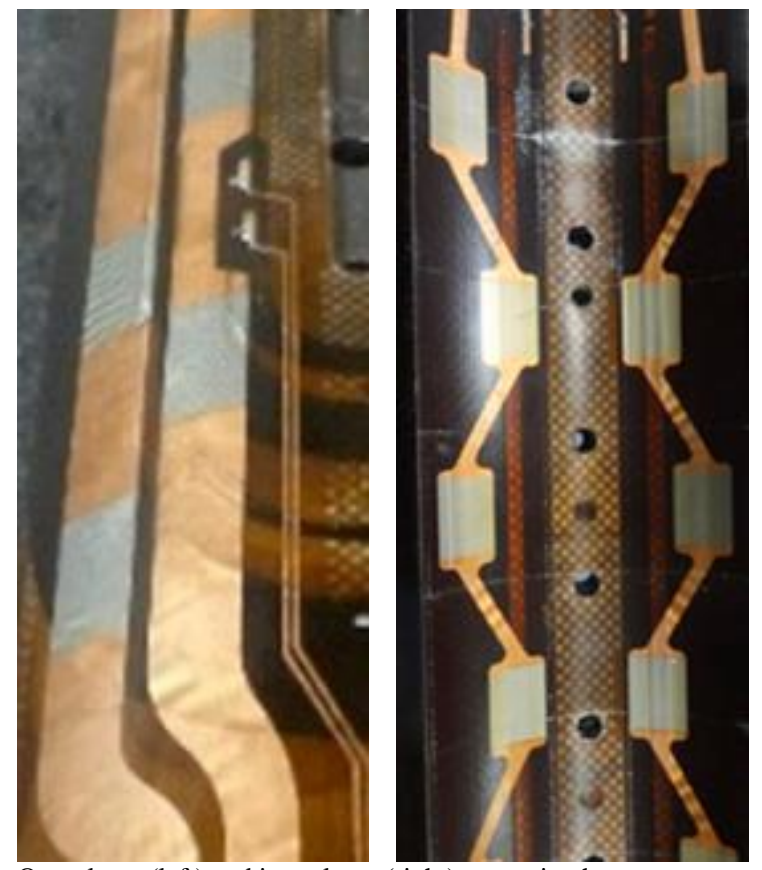

Fig 2. Outer layer (left) and inner layer (right) protection heaters

$101 \mathrm{~K}$ epoxy. External strip heaters are used on the outer surface of the tooling to reach and maintain the target temperatures for each step whereas the entire impregnation tooling set was placed in a separate furnace for degassing and epoxy cure. A minimum vacuum of $500 \mathrm{um} \mathrm{Hg}$ at $110^{\circ} \mathrm{C}$ for 8 hours is used to evacuate and dry the coil. It is then cooled to $55^{\circ} \mathrm{C}$ while maintaining vacuum. The epoxy is mixed and degassed at $55^{\circ} \mathrm{C}$ and at the same vacuum level as the coil to prevent degassing inside the coil. The degassed epoxy tank vacuum is released to atmospheric pressure with the resin flow to the coil controlled by a peristaltic pump. The exit line is closed once the epoxy is visible in about 2 hours for long coils. The system is held under atmospheric pressure and at $55^{\circ} \mathrm{C}$ for 16 hours allowing the coil to become fully saturated with epoxy. The final step is the cure cycle which consists of $110^{\circ} \mathrm{C}$ for 7 hours followed by $125^{\circ} \mathrm{C}$ for 16 hours.

\section{Coil instrumentation traces and quench heaters}

Each coil layer has eight voltage taps to detect quench. Special attention is applied to the pole turn, inner to outer layer transition, and splice between $\mathrm{Nb}_{3} \mathrm{Sn}$ cable and $\mathrm{NbTi}$ leads.

Quench protection heaters used in previous LARP magnets typically used $25 \mu \mathrm{m}$ stainless steel foil laminated with $50 \mu \mathrm{m}$ of Kapton insulation for electrical standoff. The resistivity of stainless-steel-only heaters are high for long coils and thus required high voltages to initiate a quench. Intermittently electro-plating $10 \mu \mathrm{m}$ of copper to the stainless steel foil significantly reduces the overall resistance at cryogenic temperatures and increases the power density of the noncoated heating stations [20]. To maximize thermal conductivity between coil and cryogen in the inner layer heater, the area of stainless steel is reduced and perforations are introduced covering roughly $40 \%$ of the total cross-section [13]. Pictures of impregnated outer and inner layer heaters are shown in Fig. 2.

\section{E. Coil Mechanical and Electrical Metrology}

Both QXFP01a and QXFP01b coils were measured using a

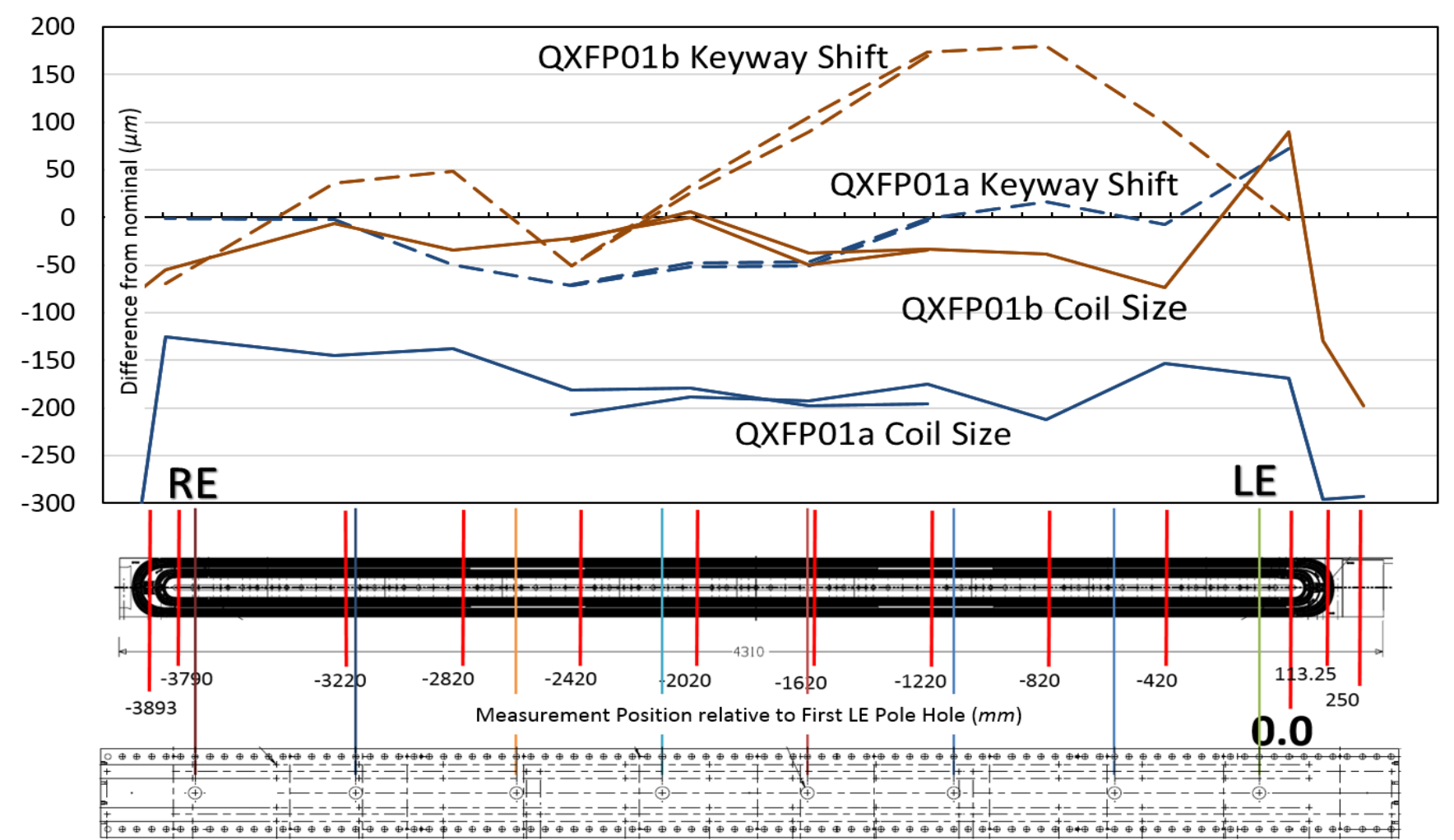

Fig. 3. Coil size and keyway shift for QXFP01a and QXFP01b as measured at Fermilab CMM. The measurement cross sections are indicated by red bars across and keyway alignment features of the impregnation tooling are also indicated. Positive direction is toward the lead end (LE) and negative toward the return end. 
3-m long CMM which requires that the QXFP coils be measured in two segments. After combining the two sets of data for each coil the measurements were analyzed and presented in Fig. 3. The coil size is quite uniform across the length for each set of tooling as seen in short coil CMM analysis [13]. The keyway shift varies more along the length

TABLE I

ELECTRIC TEST VALUES

\begin{tabular}{lccc}
\hline \hline Test & Test Level & QXFP01a & QXFP01b \\
\hline Impulse & $2.5 \mathrm{kV}$ & $2.5 \mathrm{kV}$ & $5.0 \mathrm{kV}$ \\
Coil to Trace & $2.5 \mathrm{kV}$ & $2.5 \mathrm{kV}$ & $/$ \\
Coil to Pole & $0.5 \mathrm{kV}$ & $1.0 \mathrm{kV} *$ & $3.28 \mathrm{kV} *$ \\
Coil to Endshoes & $1.0 \mathrm{kV}$ & $1.0 \mathrm{kV}$ & $5.0 \mathrm{kV}$ \\
Trace to Endshoes & $2.5 \mathrm{kV}$ & $2.5 \mathrm{kV}$ & $/$ \\
Endshoe to Endshoe & $0.6 \mathrm{kV}$ & $0.6 \mathrm{kV}$ & $5.0 \mathrm{kV}$ \\
Coil to Wedges & $/$ & $/$ & $1.26 \mathrm{kV}^{*}$ \\
Coil to End Spacers & $/$ & $/$ & $3.77 \mathrm{kV}^{*}$ \\
\hline (2ielectric breakdown
\end{tabular}

but is within the expected tolerance intrinsic to the tooling design and is also consistent with short coil CMM analysis.

The insulation scheme is quite robust for QXF coils. All end parts are plasma coated with alumina and the cable and pole insulation is roughly double that of early LARP coil designs. QXFP01b was tested to failure or to the peak value of the test equipment and exceeded all current coil test levels as shown in Table I. While testing QXFP01a, the pole was accidently shorted to the trace during the coil to trace test. This accidental short tested allowed ab1.0 kV breakdown between the coil and pole. After removing the short, the coil subsequently passed the $0.5 \mathrm{kV}$ test level.

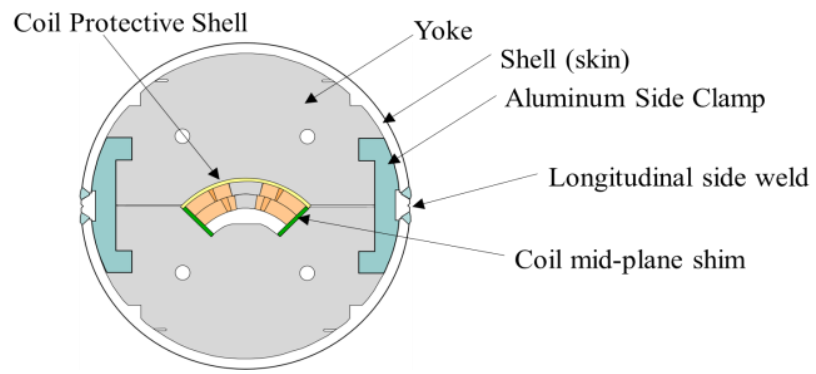

Fig. 4a. QXF Mirror cross section
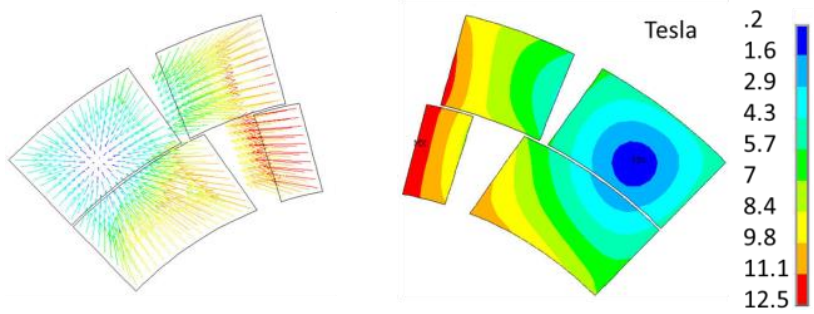

Fig. 4b. Magnetic flux distribution in a QXF coil in mirror configuration

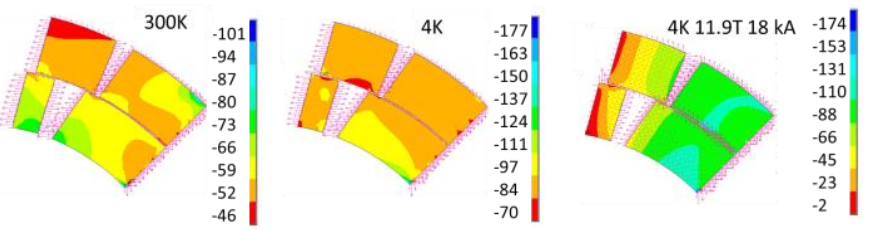

Fig. 4c. Coil azimuthal preload in a QXF mirror (MPa).
TABLE II

MiRROR AZIMUTHAL PRELOAD IN MPA

\begin{tabular}{lcccc}
\hline \hline Assembly Step & $\begin{array}{c}\text { Design } \\
\text { Preload }\end{array}$ & $\begin{array}{c}\text { Actual } \\
\text { short } \\
\text { mirror }\end{array}$ & $\begin{array}{c}\text { Actual } \\
\text { long } \\
\text { mirror }\end{array}$ \\
\hline Assembly of coil into mirror structure & 0 & 0 & 0 \\
Pre-press structure in hydraulic press & 80 & 79 & 74 \\
Insert side clamps and release press & 50 & 66 & 66 \\
Weld (or bolt) shell and release press & 70 & 77 & 98 \\
\hline \hline
\end{tabular}

\section{MIRROR ASSEMBLY}

Mirror Structures are utilized for preliminary testing of individual QXF coils. A mirror structure provides an effective method of testing the coil design features and fabrication process. Mirrors have been used in the past to test TQ, LQ, HQ and 11 Tesla Dipole coils [21-24]. The MQXFA program includes two mirror tests. MQXFSM1, containing a 1-meter long coil, was built and tested. MQXFPM1, which contains a

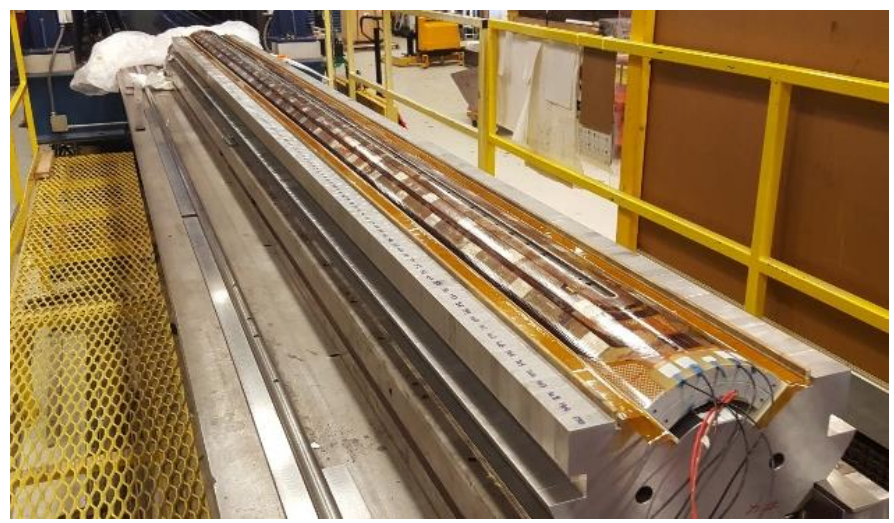

Fig. 5a. Coil installed into lower yoke

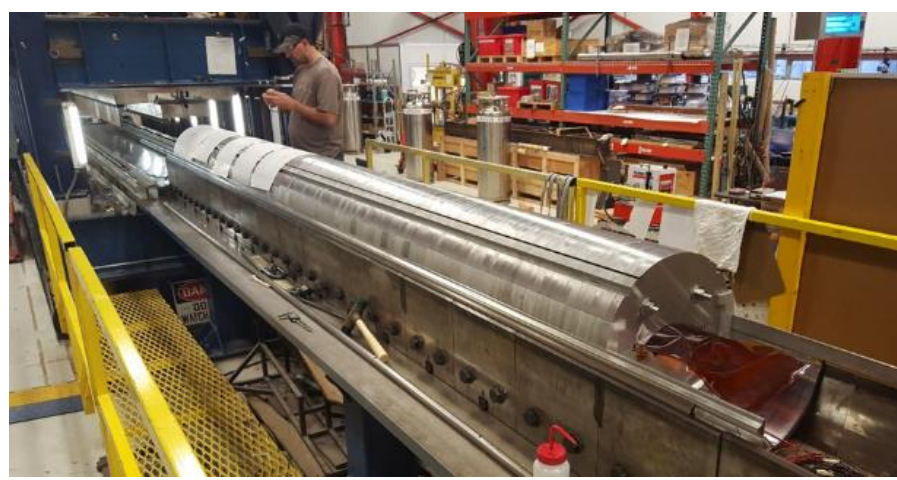

Fig. b5. Upper yoke sections being installed

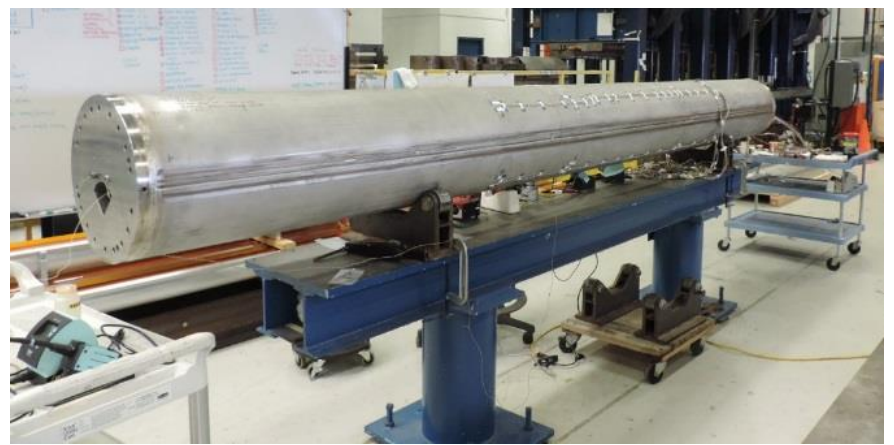

Fig. 5c. Completed MQXFPM01 
4-meter long coil, has been assembled, and will be tested in the fall of 2016. The mirror structure for the QXF coils is shown in Fig. 4a. The long mirror, which uses a welded shell, is shown. The short mirror is identical, except that the two half-shells are bolted instead of being welded.

The QXF mirror structure includes the coil, an iron yoke, an iron "mirror" to replace the three missing quadrupole coils, two aluminum side clamps, and a stainless steel shell. Despite some differences, the magnetic flux and force distribution is sufficiently representative of the full quadrupole [19]. The mirror force and flux distribution is shown in Fig. 4b. Expected azimuthal coil preload during assembly, cool-down and testing is shown in Fig. 4c.

Coil preload in a QXF mirror is provided by the combined effect of the aluminum side clamps and the stainless shell. As a first step, the coil geometry is measured on a coordinate measuring machine at several cross sections. Then, based on the measured size, it is shimmed appropriately to achieve the desired preload before being placed into the mirror structure. The preload is applied progressively during separate assembly steps for the side clamps and the shell, and is monitored by strain gauges attached to the interior surface of the titanium pole of the coil. In addition, single element quarter bridges are bonded directly to the coil and monitored during construction to validate the main azimuthal full bridges. Table I lists the steps and the azimuthal coil preload at the pole during each, as indicated by the strain gauges. Design value as well as the actual values achieved in the short and long coils are shown. Note that the pole preloads of both the short and long mirrors exceeded the design values. Since mirror design preload is well below the level which may result in cable degradation, the assembly process was implemented so that any preload variances from the design resulted in higher, rather than lower values. A total of about $3500 \mathrm{lbs}$. force per end was also applied using two bolts (bullets) at each end. Fig. 5 shows the long mirror at various stages of construction.

The MQXFPM1 assembly was completed in June 2016 and was shipped to Brookhaven National Laboratory (BNL) for testing. This mirror will serve at the first test of a full length QXF coil as well as the commissioning of the BNL test facility, which is being prepared to test full length quadrupole magnets for the MQXF program.

\section{CONCLUSION}

LARP has successfully fabricated a long MQXF practice coil and mirror coil based on a scaling up of fully tested short model coils with identical cross section. Supporting technology includes copper coated traces, updating legacy winding and curing equipment along with procedures for handling and quality checks for fabricated long coils.

A long mirror magnet (MQXFPM1) is complete and should allow quick feedback for cryogenic coil performance.

\section{REFERENCES}

[1] E. Todesco, et al., "Design studies for the low-beta quadrupoles for the LHC luminosity upgrade," IEEE Trans. App. Supercond., vol. 23, no. 3, p. 4003305, June 2013.
[2] "HL-LHC Preliminary Design Report", CERN-ACC-2014-0300, 28 November 2014.

[3] S. Feher et al., "Development and Test of LARP Technological Quadrupole (TQC) Magnet," IEEE Trans. App. Supercond, vol. 17, no. 2, pp. 1126-1129, June 2007.

[4] S. Caspi et al., "Test and Analysis of Technology Quadrupole Shell (TQS) Magnet Models for LARP," IEEE Trans. App. Supercond, vol. 18, no. 2, pp. 179-183, June 2008.

[5] G. Ambrosio, et al., "Design of $\mathrm{Nb}_{3} \mathrm{Sn}$ Coils for LARP Long Magnets," IEEE Trans. App. Supercond., vol. 17, no. 2, pp.1035-1038, June 2007.

[6] S. Caspi, et al., "Design of a $120 \mathrm{~mm}$ Bore $15 \mathrm{~T}$ Quadrupole for the LHC Upgrade Phase II," IEEE Trans. Appl. Supercond., vol. 20, no. 3, pp. 144-147, June 2010.

[7] S. Caspi, et al., "Results of $15 \mathrm{~T} \mathrm{Nb}_{3} \mathrm{Sn}$ Quadrupole Magnet HQ01 with a $120 \mathrm{~mm}$ Bore for the LHC Luminosity Upgrade," IEEE Trans. App. Supercond., vol. 21, no. 3, pp.1854-1857, June 2011.

[8] G. Chlachidze, et al., "Performance of HQ02, an Optimized Version of the $120 \mathrm{~mm} \mathrm{Nb}{ }_{3}$ Sn LARP Quadrupole", IEEE Trans. App. Supercond., vol. 24, no. 3, pp.1-5, June 2014.

[9] H. Bajas, et al., "Test Results of the LARP HQ02b Magnet at $1.9 \mathrm{~K}$," IEEE Trans. App. Supercond., vol. 24, no. 3, pp.1-5, June 2014.

[10] I. Pong, D. R. Dietderich, and A. Ghosh, "Dimensional Changes of $\mathrm{Nb}_{3} \mathrm{Sn}$ Cables during Heat Treatment," Presented at the 2015 International Cryogenic Materials Conference, C2OrF, June 28, 2015.

[11] J. DiMarco, et al., "Magnetic Field Measurement and Correction in the LARP HQ03 $\mathrm{Nb}_{3} \mathrm{Sn}$ Quadrupole," IEEE Trans. Appl. Supercond., submitted for publication.

[12] I Pong, D.R. Dietderich; A.K. Ghosh; L. Cooley, "Cable and Its Insulation for the LARP MQXF Magnet Coils," 4LPo2B-02, ASC 2016.

[13] E.F. Holik et al., "Fabrication and Analysis of 150-mm-Aperture $\mathrm{Nb}_{3} \mathrm{Sn}$ MQXF Coils," IEEE Trans. App. Supercond, vol. 26, no. 4, pp. 1-7, June 2016.

[14] S. Izquierdo Bermudez, et al., "Coil End Optimization of the $\mathrm{Nb}_{3} \mathrm{Sn}$ Quadrupole for the High Luminosity LHC," IEEE Trans. Appl. Supercond. vol. 25, no. 3, pp. 4001504, Jun. 2015.

[15] M. Yu, "Coil End Parts Development Using BEND and Design for MQXF by LARP," 2LPo2B-01, ASC 2016.

[16] F. Borgnolutti, et al., "Fabrication of a Third Generation of $\mathrm{Nb}_{3} \mathrm{Sn}$ Coils for the LARP HQ03 Quadrupole Magnet," IEEE Trans. App. Supercond., vol. 24, no. 3, p. 4002505, June 2014.

[17] G. Ambrosio, " $\mathrm{Nb}_{3} \mathrm{Sn}$ high Field Magnets for the High Luminosity LHC Upgrade Project," IEEE Trans. App. Supercond., vol. 25, no. 3, pp.4002107, June 2015.

[18] E. Rochepault, et al., "Dimensional Changes of $\mathrm{Nb}_{3} \mathrm{Sn}$ Rutherford Cables during Heat Treatment," IEEE Trans. Appl. Supercond., vol. 26, no. 4, pp. 1-5, June 2016.

[19] E. Barzi et al., "Splice testing for LHC quadrupole magnets," IEEE Trans. App. Supercond, vol. 13, no. 2, pp. 1301-1304, June 2003.

[20] E. Ravaioli et al., "Optimization of the Quench Protection System for the Nb3Sn Quadrupoles for the High Luminosity LHC," 4LPo1K-05, ASC 2016.

[21] N. Andreev, E. Barzi, R. Bossert, G. Chlachidze, V. S. Kashikhin, V. V. Kashikhin, M. J. Lamm, F. Nobrega, I. Novitski, M. Tartaglia, D. Turrioni, R. Yamada, and A. V. Zlobin, "Magnetic mirror structure for testing shell-type quadrupole coils," IEEE Trans. Appl. Supercond.,vol. 20, no. 3, pp. 288-291, Jun. 2010.

[22] R. Bossert, G. Ambrosio, N. Andreev, E. Barzi, G. Chlachidze, V. Kashikhin, M. Lamm, A. Nobrega, I. Novitski, D. Orris, M. Tartaglia, D. Turrioni, R. Yamada, and A. Zlobin, "Fabrication and test of $4 \mathrm{~m}$ long $\mathrm{Nb}_{3} \mathrm{Sn}$ quadrupole coil made of 114/127 RRP strand," in Proc. CEC/CEC, Jun. 2011, vol. 57, pp. 869-876.

[23] G. Chlachidze, et. al., "Test of Optimized $120 \mathrm{~mm}$ LARP $\mathrm{Nb}_{3} \mathrm{Sn}$ Quadrupole Coil using Magnetic Mirror Structure", IEEE Transactions on Applied Superconductivity, Vol 23, no. 3, June 2013.

[24] A.V. Zlobin et. al, "Testing of a single $11 \mathrm{~T} \mathrm{Nb}_{3}$ Sn Dipole Coil Using a Dipole Mirror Structure", presented at IPAC 2014. 